\title{
PENGARUH PENERAPAN MODEL KOOPERATIF TIPE JIGSAW DAN TGT (TEAMS GAME TOURNAMENT) TERHADAP KETERAMPILAN SOSIAL DAN KETERAMPILAN BERMAIN BOLAVOLI
}

\author{
Asep Suherman ${ }^{1)}$ \\ ${ }^{1}$ Universitas Singaperbangsa Karawang \\ email: nazwafathir@gmail.com
}

\begin{abstract}
Abstrak
Penerapan terhadap penguasaan keterampilan teknik dasar pada pembelajaran permainan bolavoli menyebabkan guru mengabaikan pentingnya pengembangan keterampilan lainnya seperti keerampilan sosial. Oleh karena itu, penerapan model pembelajaran kooeperatif tipe jigsaw dan TGT diharapkan dapat mengembangkan keterampilan sosial dan keterampilan bermain bolavoli. Tujuan penelitian ini adalah mengkaji pengaruh penerpan model pembelajaran kooperatif tipe jigsaw dan TGT terhadap keterampilan sosial dan keterampilan bermain bolavoli. Desain yang digunakan pada penelitian eksperimen ini adalah post-test only group desain yang melibatkan 70 siswa sebagai sampel penelitian yang diambil dengan menggunakan teknik cluster random saampling. Sampel dalam penelitian ini terbagi menjadi dua kelompok, yaitu kelompok A (menggunakan Cooperative Learning tipe Jigsaw) dan kelompok B (menggunakan Cooperative Learning tipe TGT). Analisis statistik yang digunakan dlam penelitian ini adalah Anova satu jalur dan Multivariante test(MANOVA). Berdasarkan penghitungn nilai rata-rata, diketahui bahwa terdapa perbedaan keterampilan sosial dan keterampilan bermain bolavoli siswa antara kelompok jigsaw dan TGT, namun berdasarkan statisti perbedaan tersebut tidak signifikan. Hasil yang sama ditunjukkan oleh hasil analisis multivriate testbahwa tidak terdapat perbedan signifikan pada keterampilan bermain bolavoli siswa kelompok jigsaw dan TGT. Berdasarkan hasil penelitian, model coopertive tipe Jigsaw dan TGT dapat direkomendasikan untuk diimplementasikan oleh guru pendidikan jasmani untuk meningkatkan keterampilan sosial dan keterampilan bermain bolavoli.
\end{abstract}

Kata kunci : cooperative learning, Jigsaw, TGT, Keterampilan Sosial, Keterampilan Bermain Bolavoli

\section{PENDAhUluan}

Guru pendidikan jasmani perlu memiliki bekal pengetahuan tentang karakteristik peserta didik dan keterampilan dalam memformulasikan metode atau model pembelajaran yang dapat mendukung tercapainya tujuan dari pendidikan jasmani itu sendiri. Menurut Bucher (Suherman, 2009: 7), tujuan dari pendidikan jasmani diklasifikasikan kedalam empat kategori yang terdiri dari: (1) perkembangan fisik; (2) perkembangan gerak; (3) perkembangan mental; dan (4) perkembangan sosial. Pendapat tersebut sangat sesuai dengan hakikat tujuan pendidikan nasional seperti yang telah dijelaskan sebelumnya yaitu mewujudkan manusia yang sehat dan berilmu serta berakhlak mulia. Oleh karena itu, guru pendidikan jasmani tidak hanya menekankan pada penguasaan keterampilan gerak dan perkembangan fisik saja sebagai indikator keberhasilan pembelajaran, melainkan juga perlu memperhatikan pengembangan aspek mental dan keterampilan sosial.

Pendidikan jasmani diyakini dapat memberikan kesempatan bagi siswa untuk: 1) berpartisipasi secara teratur dalam kegiatan olahraga, 2) pemahaman dan penerapan konsep yang benar tentang aktivitas-aktivitas tersebut agar dapat dilakukan dengan aman, 3) pemahaman dan penerapan nilainilai yang terkandung dalam aktivitas-aktivitas tersebut agar terbentuk sikap dan perilaku sportif dan positif, emosi stabil, dan gaya hidup sehat. 
Memperhatikan tujuan yang ingin dicapai dari pelaksanaan Kurikulum Tingkat Satuan Pendidikan (KTSP), maka dalam penelitian ini yang akan dikaji dan diteliti adalah proses pembelajaran pada permainan bolavoli. Permainan bolavoli merupakan salah satu materi pokok aktivitas permainan dan olahraga yang tertuang dalam kurikulum pendidikan jasmani. Aspek penting dan dominan dalam pembelajaran permainan bolavoli adalah penguasaan gerak. Terdapat beberapa teknik dasar dalam bolavoli yang perlu dimiliki oleh pemain diantaranya adalah passing, smash, block dan service.

Dalam pembelajaran permainan bolavoli, guru dituntut untuk bisa mengembangkan aspek keterampilan sosial siswa, sehingga siswa tidak hanya menguasai keterampilan gerak saja akan tetapi keterampilan sosialnya juga meningkat. Dalam meningkatkan keterampilan sosial, guru perlu memilih dan menggunakan strategi yang tepat dalam pembelajaran pendidikan jasmani khususnya pembelajaran permainan bolavoli agar tujuan yang diharapkan dapat tercapai dengan optimal.

Dalam pembelajaran permainan bolavoli, guru harus menguasai berbagai metode mengajar agar aktivitas pembelajaran menjadi lebih menarik. Berdasarkan hal tersebut, maka diperlukan suatu model pembelajaran yang dapat membantu siswa dalam mencapai hasil belajar permainan bolavoli yang terkait dengan keterampilan teknik dasar dan keterampilan sosial. Salah satu metode pembelajaran yang diharapkan dapat meningkatkan keterampilan sosial dan keterampilan bermain siswa pada permainan bolavoli yaitu metode pembelajaran cooperative learning.

Cooperative learning adalah suatu model pembelajaran yang menekankan pada kegiatan belajar berkelompok. Metzler (2000: 221) memaknai model cooperative learning sebagai strategi pembelajaran yang melibatkan siswa dalam aktivitas kelompok untuk menyelesaikan tugas tertentu dengan harapan bahwa seluruh siswa berkontribusi terhadap proses dan hasil belajar yang diperolehnya.

Dari kutipan di atas, tampak jelas bahwa pembelajaran kooperatif adalah suatu strategi pembelajaran yang membagi siswa menjadi beberapa kelompok dalam waktu dan tugas-tugas tertentu untuk kemudian bekerjasama secara efektif dan masing-masing anggota kelompoknya berkontribusi sama besar dalam proses dan pencapaian tujuan pembelajaran yang diharapkan. Pengelompokkan dalam cooperative learning menekankan pada sistem pengelompokkan heterogenitas. Kelompok heterogenitas bisa dibentuk dengan memperhatikan keanekaragaman gender, latar belakang agama, sosial, ekonomi, etnik serta kemampuan kademik. Dalam hal kemampuan akademik, kelompok pembelajaran cooperative learning biasanya terdiri dari anggota kelompok yang berkemampuan tinggi, sedang dan rendah dengan jumlah yang seimbang (Lie, 2010: 41).

Pernyataan di atas menyiratkan perbedaan nyata antara pembelajaran kooperatif dengan pembelajaran dengan metode diskusi biasa. Pada pembelajaran kooperatif, kelompok yang terbentuk harus terdiri dari siswa yang beragam dilihat dari segala aspek akademis maupun non akademis. Hal ini bertujuan untuk melatih sifat saling menghargai antar anggota kelompok dan mengurangi kesenjangan antara kelompok yang satu dengan kelompok yang lain. Selain itu, sistem pengelompokkan ini juga dapat meningkatkan rasa kepedulian antar anggota kelompok karena pengetahuan dan kemampuan salah satu anggota kelompoknya akan mempengaruhi prestasi kelompok secara keseluruhan.

Salah satu model pembelajaran kooperatif yang dapat diterapkan dalam pembelajaran pendidikan jasmani di sekolah menegah atas adalah model cooperative learning tipe jigsaw. Pada model pembelajaran kooperatif tipe Jigsaw, siswa dikelompokkan menjadi kelompok kecil yang berjumlah 4-6 orang sebagai kelompok asal, setiap anggota kelompok mendapatkan tugas spesifik yang berbeda satu dengan yang lain. Setiap anggota kelompok yang mendapatkan tugas yang sama kemudian berkumpul dengan anggota kelompok lainnya membentuk kelompok ahli untuk saling bekerjasama dalam memahami atau menyelesaikan tugas yang diberikan. Setelah siswa bekerja di dalam kelompok ahli, setiap anggota kelompok ahli kemudian kembali ke kelompok asal untuk menyampaikan tugas yang telah mereka pahami kepada anggota kelompok lainnya sehingga seluruh anggota kelompok asal memiliki pemahaman yang sama dan menyeluruh (Slavin, 2008: 237). 
Selain jigsaw, model pembelajaran kooperatif lainnya yang dapat diterapkan dalam pembelajaran permainan bolavoli yaitu model Teams Games Tournament (TGT). Dalam Cooperative learning tipe TGT, siswa bekerja dalam kelompok yang heterogen untuk mempelajari materi yang perlu dikuasai dan di akhir pembelajaran masing-masing anggota kelompok akan berkompetisi dengan anggota kelompok lainnya yang memiliki kemampuan akademis setara (homogen) di dalam sebuah turnamen akademik terkait dengan materi yang telah dipelajari (O’Mahony, 2006). Menurut Slavin (2008: 143), penerapan model kooperatif tipe TGT dapat meningkatkan keterampilan dan prestasi siswa dan interaksi pembelajaran yang positif diantara para siswa.

Dilandaskan pada uraian tersebut, maka perlu dilakukan penelitian tentang efektivitas penerapan model kooperatif pada pembelajaran permainan bolavoli dalam meningkatkan keterampilan teknik dasar dan keterampilan sosial. Terlebih lagi, penelitian terkait tentang pengaruh penerapan pembelajaran kooperatif khususnya dengan menggunakan tipe jigsaw dan TGT terhadap keterampilan bermain dan keterampilan sosial siswa SMA kelas XI pada pembelajaran permainan bolavoli belum pernah dikaji. Berdasarkan hal tersebut, maka penulis berinisiatif untuk melakukan penelitian yang berjudul " Pengaruh Penerapan Model Cooperative Learning tipe Jigsaw dan TGT (Teams Game Tournament) Terhadap Keterampilan Sosial dan Keterampilan bermain Bolavoli".

\section{METODE PENELITIAN}

Metode yang digunakan adalah penelitian pre-experimental dengan design post-test only Group Design (Salkind, 2010 : 1083). Pada desain ini, digunakan dua kelompok penelitian yang terdiri dari siswa kelompok A (pembelajaran menggunakan cooperative learning tipe Jigsaw) dan Siswa kelompok B (pembelajaran menggunakan cooperative learning tipe TGT) kemudian diamati pengaruhnya terhadap variabel yang diukur dalam hal ini keterampilan sosial dan keterampilan bermain bolavoli. Instrumen penelitian yang digunakan yaitu tes keterampilan bermain bolavoli dan Angket yang digunakan pada saat pre-test dan post-test. Tes keterampilan bermain bolavoli dalam penelitian ini dilakukan dengan cara mengobservasi keterampilan bermain siswa dengan skala rating berdasarkan format penilaian FIVB yang dikutip dari Yudiana (2010: 103-105) sedangkan Angket digunakan untuk menjaring keterampilan sosial siswa. Indikator keterampilan sosial siswa yang dijaring melalui angket terdiri dari keterampilan dasar berinteraksi, berkomunikasi, membangun tim/ kelompok dan menyelesaikan masalah yang diadaptasi dari Maryani (2011:20). Setiap indikator diberikan skor dengan skala 4 s/d 1 berdasarkan kriteria skoring yang telah ditetapkan. Data yang diperoleh kemudian dianalisis dengan menghitung nilai rata-rata pretes dan postes dan penghitungan statistik menggunakan Anova dan Manova. 
3. HASIL DAN PEMBAHASAN

A. HASIL PENELITIAN

1. Analisis Data Keterampilan Sosial Siswa pada Pembelajaran Kooperatif Tipe Jigsaw dan TGT

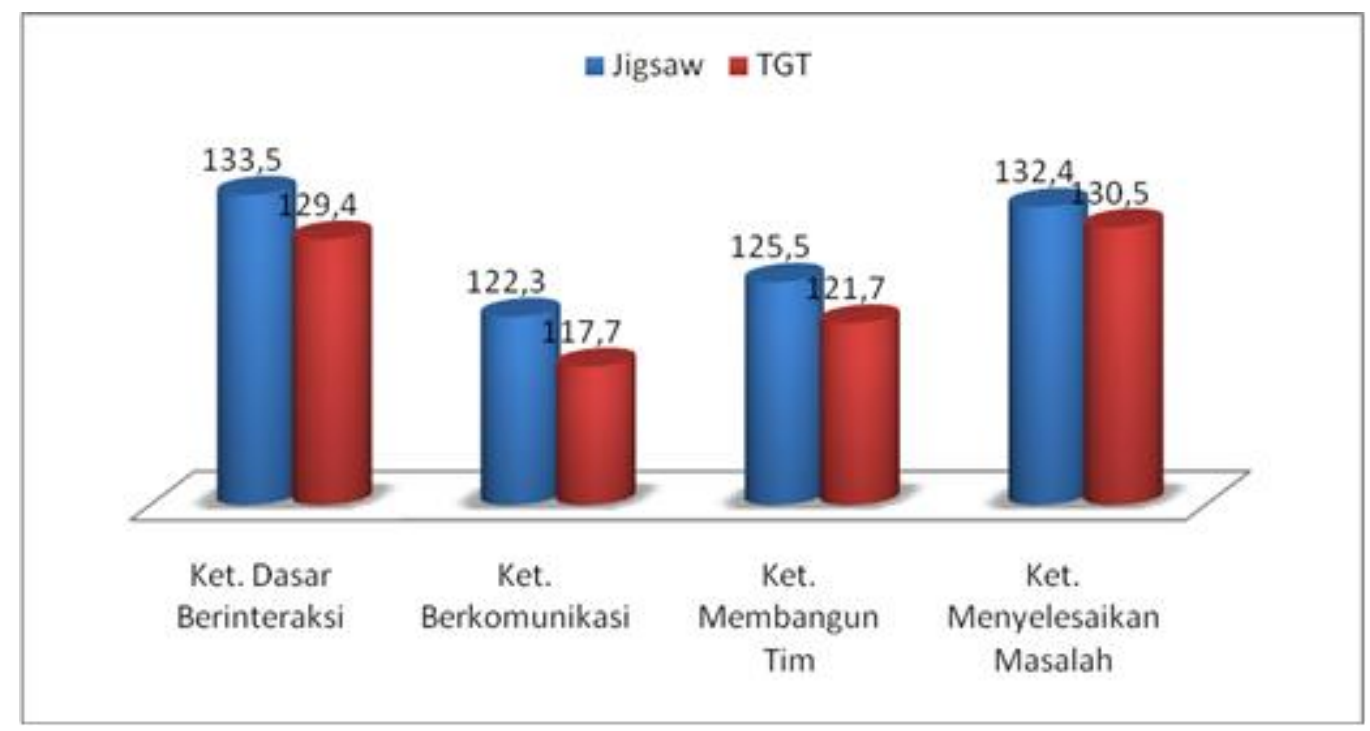

Gambar 1. Perbandingan Nilai Rata-rata Keterampilan Bermain Bolavoli Siswa Kelompok Jisaw dan TGT

Berdasarkan perbandingan nilai rata-rata siswa kelompok jigsaw dengan TGT, dapat dirumuskan kesimpulan sementara bahwa siswa pada kelompok jigsaw memiliki keterampilan sosial yang lebih baik dibanding siswa pada kelompok TGT. Namun jika diperhatikan kembali, selisih nilai rata-rata keterampilan sosial pada setiap indikator tidak terpaut jauh. Oleh karena itu, analisis data keterampilan sosial siswa perlu dilanjutkan pada analisis statistik menggunaan Anova satu jalur untuk mengetahui perbedaan signifikan nilai rata-rata keterampilan sosial siswa antara kelompok jigsaw dengan TGT.

Hasil analisis uji Anova satu jalur terhadap data keterampilan sosial siswa dapat dilihat pada Tabel 1 sebagai berikut:

Tabel 1. Hasil Uji Anova Satu Jalur Data Keterampilan Sosial Siswa

Kelompok Jigsaw dan TGT

\begin{tabular}{|c|c|c|c|}
\hline $\begin{array}{c}\text { Kelompok } \\
\text { Penelitian }\end{array}$ & $\begin{array}{c}\text { Nilai } \\
\text { Sign. }\end{array}$ & $\begin{array}{c}\text { Nilai } \\
\text { Alpha } \\
(\alpha)\end{array}$ & Keterangan \\
\hline $\begin{array}{c}\text { Siswa } \\
\text { Kelompok Jigsaw } \\
\text { dan TGT }\end{array}$ & 0,906 & 0,05 & $\begin{array}{c}\text { Tidak } \\
\text { Signifikan }\end{array}$ \\
\hline
\end{tabular}


Berdasarkan tabel di atas, diketahui bahwa nilai signifikansi data keterampilan sosial adalah sebesar 0,906 lebih besar dari $\alpha=0,05$. Berdasarkan kriteria hipotesis uji anova, jika nilai sign. $(0,906)>\alpha(0,05)$ maka Ho diterima dengan kata lain $\mu 1=\mu 2$ atau tidak terdapat perbedaan hasil keterampilan sosial antara siswa yang mengikuti pembelajaran kooperatif tipe jigsaw dengan TGT.

\section{Analisis Data Keterampilan Bermain Bolavoli Siswa Pada Pembelajaran Kooperatif Jigsaw dan TGT}

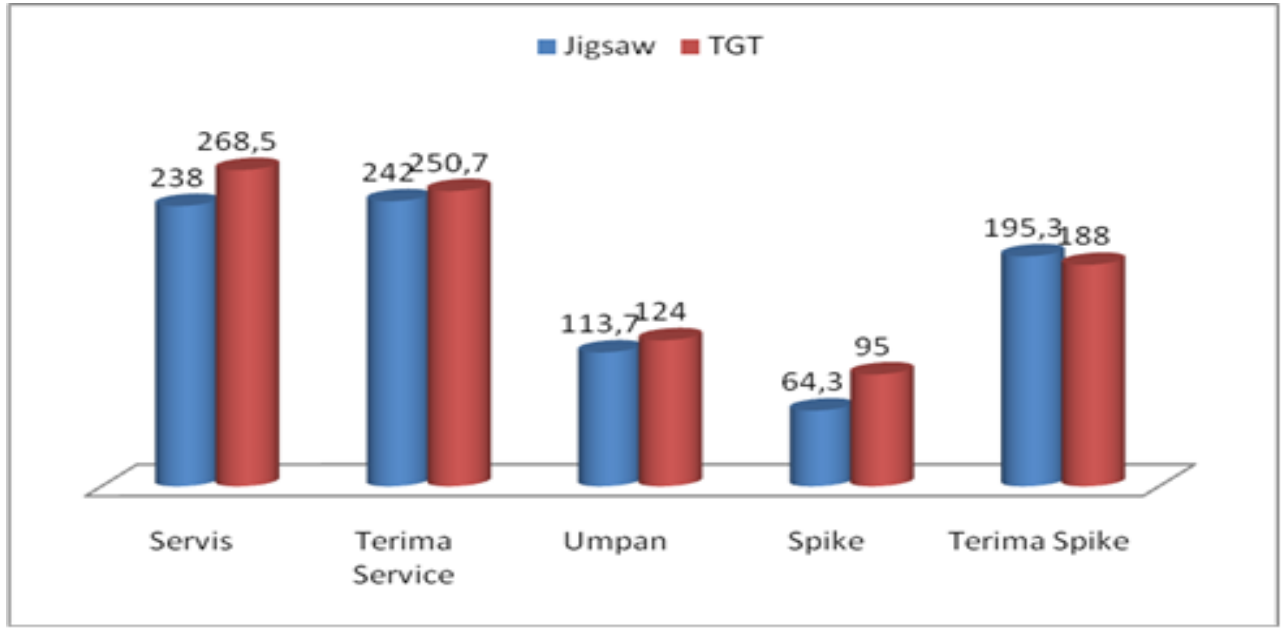

Gambar 1. Perbandingan Nilai Rata-rata Keterampilan Bermain Bolavoli

Siswa Kelompok Jisaw dan TGT

Secara umum, nilai rata-rata keterampilan bermain bolavoli siswa kelompok TGT lebih besar dibanding siswa kelompok Jigsaw. Namun hal ini bukan berarti bahwa nilai rata-rata keterampilan bermain bolavoli antara siswa kelompok jigsaw dengan TGT berbeda signifikan. Oleh karena itu, perlu dilakukan analisis statistik Anova untuk mengetahui perbedaan signifikan antara keterampilan bermain bolavoli siswa kelompok jiigsaw dengan TGT.

Hasil analisis uji Anova satu jalur terhadap data keterampilan bermain bolavoli siswa dapat dilihat pada Tabel 2.

Tabel 2. Hasil Uji Anova Satu Jalur Data Keterampilan bermain bolavoli

Siswa Kelompok Jigsaw dan TGT

\begin{tabular}{|c|c|c|c|}
\hline $\begin{array}{c}\text { Kelompok } \\
\text { Penelitian }\end{array}$ & $\begin{array}{c}\text { Nilai } \\
\text { Sign. }\end{array}$ & $\begin{array}{c}\text { Nilai } \\
\text { Alpha }\end{array}$ & Keterangan \\
\hline $\begin{array}{c}\text { Siswa } \\
\begin{array}{l}\text { Kelompok Jigsaw } \\
\text { dan TGT }\end{array}\end{array}$ & 0,797 & 0,05 & $\begin{array}{c}\text { Tidak } \\
\text { Signifikan }\end{array}$ \\
\hline
\end{tabular}

Dari penghitungan uji Anova terhadap data keterampilan bermain bolavoli siswa pada kelompok jigsaw dan TGT, diperoleh hasil bahwa nilai signifikansi data keterampilan bermain bolavoli adalah sebesar 0,797 lebih besar dari $\alpha=0,05$. Berdasarkan kriteria hipotesis uji anova, jika 
nilai sign. $(0,797)>\alpha(0,05)$ maka Ho diterima dengan kata lain $\mu 1=\mu 2$ atau tidak terdapat perbedaan keterampilan bermain bolavoli antara siswa yang mengikuti pembelajaran kooperatif tipe jigsaw dengan TGT.

\section{Analisis data Keterampilan Sosial dan Keterampilan Bermain Bolavoli Siswa pada Pembelajaran Kooperatif Tipe Jigsaw dan TGT}

Hasil analisis uji Manova data keterampilan sosial dan keterampilan bermain bolavoli siswa dapat dilihat pada Tabel 3.

Tabel 3. Uji Manova Data Keterampilan Sosial dan Keterampilan Bermain Bolavoli Siswa pada Pembelajaran Kooperatif Jigsaw dan TGT

\begin{tabular}{|c|c|c|c|c|}
\hline Jenis Tes & Jenis data & Nilai & Nilai $\alpha$ & Keterangan \\
\hline $\begin{array}{c}\text { Multivariat } \\
\text { e Test }\end{array}$ & $\begin{array}{l}\text { Data } \\
\text { Keterampilan Sosial } \\
\text { dan Keterampilan } \\
\text { Bermain Bolavoli }\end{array}$ & 0,959 & 0,05 & $\begin{array}{c}\text { Tidak } \\
\text { signifikan }\end{array}$ \\
\hline $\begin{array}{c}\text { Test of } \\
\text { Between- } \\
\text { Subject effect }\end{array}$ & $\begin{array}{c}\text { Keterampilan } \\
\text { Sosial }\end{array}$ & 0,906 & 0,05 & $\begin{array}{c}\text { Tidak } \\
\text { signifikan }\end{array}$ \\
\cline { 2 - 3 } & $\begin{array}{c}\text { Keterampilan } \\
\text { Bermain Bolavoli }\end{array}$ & 0,797 & & $\begin{array}{c}\text { Tidak } \\
\text { Signifikan }\end{array}$ \\
\hline
\end{tabular}

Berdasarkan analisis data keterampilan sosial dan keterampilan bermain bolavoli dilihat dari perbandingan nilai rata-rata keterampilan sosial, maka diperoleh informasi bahwa nilai keterampilan sosial siswa kelompok jigsaw secara umum lebih besar dibanding siswa kelompok TGT. Sedangkan data keterampilan bermain bolavoli siswa pada kelompok TGT memiliki nilai rata-rata yang lebih besar dibanding siswa kelompok jigsaw kecuali pada indikator keterampilan menerima spike. Jika diperhatikan dengan seksama, nilai rata-rata keterampilan sosial dan keterampilan bermain bolavoli siswa pada masing-masing indikator dapat dikatakan baik. Hal ini berarti penerapan kedua model pembelajaran kooperatif dapat meningkatan keterampilan sosial dan keterampilan bermain bolavoli. Namun untuk mengetahui signifikansi perbedaan pengaruh kedua model tersebut, maka dilakukan uji Anova dan Manova. Penghitungan analisis statistik dengan menggunakan uji Anova maupun Manova menunjukkan bahwa tidak ada perbedaan signifikan antara keterampilan sosial dan keterampilan bermain bolavoli antara siswa kelompok jigsaw maupun pada kelompok TGT. Artinya perbedaan penerapan model pembelajaran kooperatif tidak mempengaruhi perbedaan perolehan keterampilan sosial dan keterampilan bermain bolavoli.

\section{KESIMPULAN}

Berdasarkan hasil analisis dan interpretasi terhadap data penelitian keterampilan sosial dan keterampilan bermain bolavoli pada pembelajaran permainan bolavoli dengan cooperative learrning tipe jigsaw dan TGT, diperoleh beberapa jawaban dari rumusan masalah yang ada. Jawaban tersebut dapat dirumuskan kedalam beberapa kesimpulan sebagai berikut. 
1. Terdapat perbedaan keterampilan sosial antara siswa SMA St. Aloysius kelas XI yang belajar melalui penerapan cooperative learning tipe jigsaw dengan TGT pada permainan bolavoli dilihat dari penghitungan nilai rata-rata angket keterampilan sosial, namun secara statistik perbedaan tersebut tidak signifikan.

2. Terdapat perbedaan keterampilan bermain bolavoli antara siswa SMA St. Aloysius kelas XI yang belajar melalui penerapan cooperative learning tipe jigsaw dengan TGT pada permainan bolavoli dilihat dari penghitungan nilai rata-rata skor keterampilan bermain bolavoli, namun secara statistik perbedaan tersebut tidak signifikan.

3. Terdapat perbedaan antara keterampilan sosial dan keterampilan bermain bolavoli siswa SMA St. Aloysius kelas XI yang belajar melalui penerapan cooperative learning tipe jigsaw maupun TGT pada permainan bolavoli dilihat dari penghitungan nilai rata-rata angket keterampilan sosial dan skor keterampilan bermain bolavoli, namun secara statistik kedua perbedaan tersebut tidak signifikan. 


\section{REFERENSI}

Lie, A. (1999). “Metode Pembelajaran Gotong Royong”. Surabaya : CV Mitra Media \& LPPKM VR Petra.

Maryani, E. (2011) Pengembangan Program Pembelajaran IPS untuk Peningkatan Keterampian Sosial. Penerbit Alfabeta, Bandung.

Metzler. (2000).Instructional Models For Physical Education. Allyn and Bacon. USA.

Salkind. (2010). Methods in Educational Research: From Theory to Practice. San Fransisco: Jhon Wiley \& Son inc.

Slavin, Robert E. (2008). Cooperative Learning Theory, research, and Practice.USA : The Jhons Hopkins University.

Suherman, A (2009). Revitalisasi Pengajaran dalam Pendidikan Jasmani. Bandung: CV. Bintang WarliArtika.

Yudiana, $\quad$ (2010). Implementasi Model PendekatanTaktisdanTeknisDalamPembelajaranPermainanBolavoliPadaPendidikanJasmani Siswa SMP (TinjauanPerbedaanKeterampilanTeknikDasardanBermainBolavoli, sertaKeterampilanBerpikirKritisSiswa SMPN 4 Kota Bandung).Disertasi. Prodi POR Pascasarjana UPI. 